\title{
Health of subsistence fishermen and challenges for Occupational Health Surveillance
}

Paulo Gilvane Lopes Pena ${ }^{1}$

Carlos Minayo Gomez ${ }^{2}$

${ }^{1}$ Departamento de Medicina Preventiva, Faculdade de Medicina, Universidade Federal da Bahia. Av. Reitor Miguel Calmon s/n, Vale do Canela. 40000-000 Salvador BA Brasil.pena@ufba.br ${ }^{2}$ Centro de Estudos da Saúde do Trabalhador e Ecologia Humana, Escola Nacional de Saúde Pública, Fiocruz.
Abstract There are approximately a million subsistence fishermen in Brazil whose activities expose them to severe occupational hazards without adequate health protection. This article conducts an analysis of working conditions and health risks faced by subsistence fishermen and outlines challenges to the implementation of Occupational Health Surveillance (VISAT) actions. The methodology is based on qualitative analysis of risks and working conditions through observation and interviews, and diagnosis of occupational illnesses with clinical evaluation. Mobile teams conducted eight years of activities together with fishing communities throughout the state of Bahia. The results revealed the challenge of surveying a traditional self-employed category with relative management autonomy. Fishermen face precarious living conditions without access to occupational health services. They are exposed to thirty work-related illnesses without protection, diagnosis, treatment and social security coverage. The conclusion reached is that there is a need for intersectorial VISAT action to reduce excessive working hours, organization of the Unified Health System (SUS) for acknowledgement of occupational illnesses and guaranteeing social security rights through actions focused on health education.

Key words Occupational health, Subsistence fisherman, Occupational hazards, Occupational illnesses 


\section{Introduction}

This article contains an analysis of the working and health conditions of subsistence fishermen based on research and university work carried out in the fishing region of the State of Bahia. Prominence is given to the challenges that exist to implementing occupational health surveillance programs (VISAT) among these kinds of workers who are engaged in traditional forms of production and who survive in precarious economic and social conditions.

According to official data, there are 957,000 subsistence fishermen registered in Brazil ${ }^{1}$. The Brazilian Constitution of 1988 guaranteed this category social security rights as a special class, among them accident insurance, because of the vulnerability of their lives in a social and cultural context marked by unsafe and unhealthy working conditions and a lack of infrastructure for the protection of health. They live with the environmental degradation of fishing grounds through contamination by untreated sewage, industrial chemical pollution and agro-toxic substances. The fishing grounds are also threatened by the expansion of tourism associated with property speculation and major projects for ports and industries. In addition, they suffer from the ongoing effects of climate change that threaten the resources on which they depend for their living. Among these difficulties, SUS programs figure in an isolated manner, without consideration for the traditional ways of life and work of these categories of workers. Ensuring the right to health of these workers represents great challenge to public health programs, of which VISAT programs form part.

Subsistence fishing is based on the family structure, and is a productive system inscribed in traditional cultural practices. This ancient method of production is founded on a durable local fishing network, with its tasks and divisions of labor and modes of solidarity and cooperation that contain the economic objectives for survival. It differs from waged work where the family represents a consumer structure, dependent on profit not from what it produces, but from the sale of its labor in exchange for a wage ${ }^{2}$. With subsistence fisherman, the method of production organizes and mobilizes the labor force contained within family relationships, compounding it with the process of social reproduction ${ }^{3}$. Solidarity reigns equally in the organization of the family and the traditional work processes. The management of activities possesses hierarchical links of kinship, characterized as a species of paternal or matriarchal vertical self-management that is different from the participative forms found in cooperatives based on horizontal work relationships ${ }^{4}$.

Another important difference in family subsistence work concerns the preservation of the notion of self-employment ${ }^{5}$; in other words, there is no such thing as an unemployed subsistence fisherman or shellfish gatherer. There is a culture of social inclusion of family members in the work, who absorb the traditional knowledge and learn to carry out tasks without the need for formal education, and for this reason there is no moment of admission when a person is included in the workforce. This possibility for the preservation of employment has been increasingly appreciated in modern societies in the light of the suffering of the unemployed worker.

The division of family labor is predominantly social, not technical, and involves work by early developing children and adolescents or even by late developers, as well as the division of labor between the sexes. Women are generally restricted to the gathering of shellfish, in addition to their domestic duties, while the men deal with the fishing itself. Shellfish and fish are perishable products that require an infrastructure for hygienic cold storage, which the small producer does not possess. Because of this, it is common for subsistence fishermen to take from his catch the part required to ensure the survival of his family and sell the excess to a middleman, in a similar way to what occurs in the case of family farming ${ }^{3,6}$. The need to sell the product quickly means the acceptance of derisory prices imposed by the financial middleman. And the job also involves a long working day that can reach 14 or 16 hours, without days off at weekends or holidays. This situation is similar to that which existed in the early days of the industrial revolution in England, with its drastic consequences for workers' health. In such a commercial situation, there are still very few cooperative experiments or delivery of the product direct to the consumer.

These factors express themselves in a health situation of epidemiological proportions, consisting of transmissible diseases and conditions typically found in poverty, associated with chronic degenerative diseases, drug abuse ${ }^{7}$ and the dangers to health resulting from working procedures. The implementation of actions for the protection of health falls within the context of family decisions, but because of their precarious economic situation, there are no resources for individual and collective protection measures against ac- 
cidents and occupational illnesses. There is also no system of periodical examinations for the prevention of occupational illnesses. The care available under SUS does not generally diagnose these work related threats, nor does it give any guidance on appropriate preventive measures. Thus the morbidity picture remains invisible from an epidemiological point of view, not only because of the under-notification of illnesses, but also because of the absence of adequate records relating to this mode of non-waged work. The conception of the family as a consumer unit predominates in practices under the Family Health Strategy $y^{8}$. As a result, the members of a family production unit, as well as having no guarantee of full health care, do not enjoy any social security rights of sickness pay as a result of accidents or retirement through invalidity, because the problems need to be diagnosed as work-associated.

\section{The work of fishermen and health risks}

The data presented here was obtained from a qualitative study and during a process of intervention carried out between 2005 and 2014 in nine communities of fishermen with populations of between 800 and 20,000 inhabitants, all situated on the coast of Bahia. The populations, made up basically of fishing and shell fishing families, were assisted by multi-disciplinary teams from the School of Nutrition, the Faculty of Medicine and the Occupational Illnesses Clinic (SESAO) of the Federal University of Bahia (UFBA) Hospital. In 2013, the project also had the participation of researchers from the Oswaldo Cruz Foundation - FIOCRUZ and the Federal University of Rio de Janeiro (UFRJ), with the aim of producing a documentary and other educational material.

In 2004, in a series of surveys and other research by UFBA, it was noted that there was a need to investigate the generalized complaints of painful symptoms by fishermen and shellfish gatherers, which could have originated in their work activities, especially in the gathering of shellfish. A review of the literature indicated that no clinical or epidemiological studies existed with regard to this category of workers, and the studies found referred to industrial fishermen in developed countries, whose work processes included modern technological resources ${ }^{9,10}$.

Initially the observations revealed features typical of subsistence family work in situations of economic and social vulnerability, with low levels of education and work performed by children, adolescents and elderly people, especially in shellfish gathering activities. In analyzing the risks and working conditions, observation was made of the exhausting work patterns and working days of between twelve and sixteen hours, in inhospitable areas such as mangrove swamps and in excessive heat. The project also witnessed activities with repetitive movements and accelerated rhythms, excessive burdens on the upper limbs and the absence of breaks. These situations were conditioned by the times of the tides and by the need to gather the greatest possible volume of produce, which would allow economic survival through the sale of the produce to middlemen. Thus, the working day is only six hours at the ebb tides, together with an average of four or five hours, again of repetitive movements, spent in peeling the shellfish at home after they have been gathered.

A qualitative evaluation of the risks, supported by a review of the literature ${ }^{10}$, indicated the possible occurrence of approximately thirty work related illnesses in subsistence fishing, of the 200 illnesses currently recognized by the Ministry of Health and Social Security ${ }^{11}$. The risks relate to the following categories: solar radiation and risk of neoplasms, cataracts, etc; high atmospheric pressure in diving activities and the possibility of decompression sickness, ear damage (barotrau$\mathrm{ma}$ ), labyrinthitis and hearing problems; humidity and mud in the mangrove swamps, with the risk of mycotic dermatitis and onychomycosis, genital or urinary inflammations, and allergies; bad weather, rain and cold, with the risk of respiratory infections, pharyngitis, etc; biological risks related to working in mangrove swamps and the possibility of contamination by transmissible diseases or dermatitis from contact with marine animals and plants; chemical risks from the fumes given off from the cooking of shellfish, with the possibility of respiratory illnesses, rhinitis and allergic sinusitis etc; ergonomic risks to the spinal column, caused by carrying weights, harmful postures and excessive repetitive movements. Here, particularly, there is ergonomic evidence of RSI risks, arising principally from overwork with an excess of movement and repetitive effort, demanded by the work rhythms and accelerated by the hard conditions of survival.

As regards work related accidents, fishermen and shellfish gatherers face a variety of risks, such as: drowning, including in the mud of the mangrove swamps; cuts or wounds sustained while handling shellfish and fish with various fishing instruments, or while cutting wood or preparing shellfish; insect bites; bites from snakes or other 
venomous terrestrial or marine creatures. These risks are particularly serious when they affect children, pregnant women or old people.

\section{The diagnosis of work related illness and social security rights}

Evidence of precarious working conditions, excessive exposure to organizational and environmental risks, and the lack of access to occupational health services led to the organization by the SESAO team in 2006 of a Forum for Participation and Social Control in Occupational Health in the Subsistence Fishing Industry. Its aim was to plan activities relating to occupational health in the fishing industry, involving a variety of institutions such as the State Reference Center for Occupational Health - CESAT, Social Security, the State Health Department, the Federal Ministry of Health and Bahia Fishing, as well as representatives of the fishermen and shellfish gatherers of the State. This Forum gave rise to a social movement for planning actions by SESAO aimed at attending to the needs of workers in the fishing communities, with the participation of community leaders, mainly representing shellfish gatherers.

Given the lack of mobile health services, the SESAO team decided that the initial focus should be on diagnosis, treatment and rehabilitation in RSI cases, because the team had the qualified personnel and technical resources to achieve results. As regards the diagnosis of other ailments, there were, for example, no personnel qualified in hyperbaric medicine and no pressurized chambers for treating and rehabilitating those suffering from illnesses caused by the atmospheric pressures encountered in fishing involving diving. The patients lived far from urban centers, without access to the Family Health Units and CERESTs that would be able to coordinate the system of referrals and counter-referrals for medical treatment. This underlined the SUS organizational principle of resolving problems through the health care provided by mobile units, in view of the fact that there was a need for the multi-disciplinary care of the patients from fishing communities on the same day as the initial attendance. Exams were therefore carried out on this first day by personnel qualified in clinical evaluation and occupational medicine, nursing, the collection of material for laboratory examination, and there were consultations with ultrasound imaging specialists, neurologists using electromyography and physiotherapists. In this way, all the essential steps were taken on the same day for diagnosis, treatment and social security referral, with the CAT (official accident notification form) for sickness leave in appropriate cases.

A study carried out by Kaerlev ${ }^{9}$ disclosed a high incidence of musculo-skeletal lesions among 4,570 fishermen treated by hospitals in Denmark. However, in this study, which was the only hospital research discovered on the diagnosis of RSI in fishermen, there were no indications as to the procedures used. Thus it became necessary to formulate clinical protocols for RSI diagnosis, oriented towards the subsistence fishing business. On the basis of the indications that already existed in the relevant literature ${ }^{12-14}$, clinical and epidemiological links were specified and compared with the results of ergonomic analyses of the workplace, so that, in cases where there was a recommendation for sick leave of more than fifteen days, the social security procedures could be complied with by the issue of a report and a CAT.

The essence of the protocol consisted in seeking links between the pathology and the work related risks in the particular environment of subsistence fishing. Guidelines were devised in systemized sections for: medical diagnosis of the illness through clinical links centered on the relationship between occupational history and symptoms, with the respective clinical findings and supplementary tests, including imaging and electromyography; the epidemiological risk at work through the ergonomic study of the activities involved in fishing and shellfish gathering; a biomechanical study of the work (static posture and muscular and articular complexes required for the work and dynamic posture and muscular and articular complexes involved); specification of activities required for gathering or peeling shellfish, transport, pre-cooking, removal of shells; summary of causal links between activities and pathologies; procedures for kinetic/functional physiotherapeutic diagnosis and analysis of functional capacity (scope of movement possible or restricted, together with a definition of degree of gravity in order to define incapacity and referral to Social Security); therapeutic plan; procedures for recognition for social security purposes, with issue of CAT and reports; and professional rehabilitation, bearing in mind the particular circumstances of a self-employed subsistence worker.

These guidelines led to the diagnosis of approximately 800 cases of RSI among subsistence fishermen, principally shellfish gatherers, during 
the seven years of activity by SESAO, with approximately $20 \%$ of sufferers referred to Social Security. This was a unique case study in Brazil and has guided similar operations in other fishing regions. In the Social Security statistical data for 2012, 163,953 cases of work related illnesses were recorded. For the formal category classed as fishing and aquaculture, between 2010 and 2012, only five cases of work related illness were recorded with CAT and 135 without CAT. In INSS data on work related illnesses, using the Brazilian Classification of Occupations (CBO), as applicable to "fishermen and forest workers", the situation as regards under-notification persists, because only 32 cases of work related illness are recorded among 16,839 notifications for other categories, with no registration without CAT in $2012^{15}$. This is an unfair Social Security situation and the deconstruction of the epidemiological invisibility of work related illnesses in this category will involve a long process of public action.

The first shellfish gatherers applying to INSS with a CAT for a certificate of sick leave faced discrimination, hostility and resistance in gaining acceptance for the social security causal nexus. For many of the administrative and medical staff, the shellfish gatherers should have appeared ragged and covered in mud in order to be considered as having come from doing such work. When they were attended, because there were not enough diagnoses of work related illnesses in this category, the data system did not trigger the procedures for the Epidemiological Technical Nexus, and the alternative recognition procedure relied on the classic method of proving the causal nexus with occupational evidence of exposure to excessive repetitive movements and other risks. The lack of preparedness on the part of medical experts to recognize situations outside the normal parameters made them treat the shellfish gatherer patients as malingerers interested in illegally obtaining benefits, thereby strengthening the prejudice still more. They thus experienced a denial of their rights: the failure to accept a work related illness by Social Security encountered by non-waged categories of workers, as identified by Verthein and Gomez ${ }^{16}$.

\section{The experiment of occupational health mobile units}

According to the $\mathrm{WHO}^{17}$, there are 2.2 billion workers in the world without access to occupational health services, which has become one of the biggest challenges to the global guidelines for occupational health issued to member countries. In Brazil, the figure can amount to two thirds of the economically active population, including informal workers, the total number of those employed in family farming and subsistence fishing, who are almost exclusively users of SUS. In the face of this situation, SESAO developed a method of occupational health activity known as "itinerant action", a feature of which was the movement of a multi-disciplinary team and basic infrastructure from the mobile service to provide some types of attendance among fishing communities and their workplaces.

A multi-disciplinary team comprising doctors, nurses and nursing technicians, physiotherapists, nutritionists and administrative staff relocated, in order to work for one or two days attending communities of fishing workers by prior arrangement. The work was divided into two groups, in which one part of the team analyzed the work activities involved in fishing and shell fishing in order to identify occupational risks and any local peculiarities in order to establish causal relationships with potential health threats. The main aim was to describe the ergonomic conditions and environmental risks for the purposes of clinical causation and social security reports, as well as establishing preventive measures and health education practices. A second group of professionals improvised consulting and meeting rooms for the examination and diagnosis of suspected RSI cases, health educational programs and guidance in physiotherapy and nutrition. All these activities had the participation of leaders of the subsistence fishing communities and, in some cases, professionals from Family Health Units who were aware of the need to learn about work related illnesses and accidents. Finally, and not least importantly, the retention of records with regard to mobile and hospital attendance with SESAO was organized for serious cases that needed supplementary tests and social security referral.

This program lasted five years and operated in more than 20 fishing communities. The results were significant, both as regards the accumulation of knowledge with regard to the various working procedures and risks in the same occupational category, and with regard to the mobilization of communities for the purposes of visiting the mobile team and also the diagnosis of work related illnesses, especially RSI. Dozens of fishing communities received these mobile units, which treated between 30 and 150 fishermen and shellfish gatherers with predominantly painful 
symptoms related to their work. The scenes of those with complaints seeking medical attendance frequently resembled health campaigns for the control of major epidemics, a situation that surprised everybody due to the numbers involved.

\section{Challenges for the implementation of VISAT programs}

The situation revealed here shows the need for devising strategies for VISAT for the purposes of protecting the health of subsistence fishermen. With this in mind, we set out below certain guidelines, many of which are the result of the training/action programs carried out with these workers, which could also be extended to nonwaged family farming work:

1- A reduction in exhausting and excessive working hours. Such a reduction would materially affect the time of exposure to risk and excessive weight carrying arising from the working methods. However, as opposed to the gains achieved by salaried workers, there are no immediate prospects in this direction in the case of subsistence fishing. The exorbitant proportion of the profits appropriated by the middleman is responsible for the long hours, the pressurized rhythm of work, the difficulty of taking breaks and the other conditions that constitute threats to health. In addition, there are the environmental problems that affect the fishing grounds and are responsible for driving people away to other areas.

Any elimination of the middleman or reduction in working hours presupposes the reorganization of work processes. For this purpose it would be necessary to incorporate the advances obtained by existing experiments in the context of economic solidarity, cooperative ventures or other forms of association. This would mean changing or reviewing traditional cultural values, and improving educational conditions that hinder the acceptance of alterations in working methods or the use of new technologies. A clear example would be the fitting of motors to boats and canoes. This could significantly reduce the travelling time of shellfish gatherers, who row for two or three hours per day to reach the shellfish grounds.

A prospective reduction in the working day reflects the VISAT priorities in improving working conditions in order to promote health ${ }^{18}$. It would be a complex procedure, because it would depend essentially on convincing self-employed workers who have centuries of tradition in the business of fishing. In this context, lasting educational programs with social support take on a central role in the introduction of improvements leading to a reduction in working hours.

2 - Coordination of practices in the fishing grounds with the territorial range of SUS. The fishermen often work in mangrove swamps and sandy beach areas that are contaminated by sewage, industrial effluent or agro-toxic chemicals or destroyed by property speculation. These are examples of current threats to the areas of fishing and shellfish gathering, characterized as workplaces owned by the community or the general public. These threats need to be considered in the territorial organization of the Family Health Units for simultaneous action to protect health, the environment and the territorial rights of traditional populations.

3 - Consideration of the particular characteristics of social participation in VISAT programs. Subsistence fishermen are organized by means of colonies, associations and religious movements, but they do not have the political power associated with waged workers and their trade unions. However, there is a growing national movement for the defense of fishing grounds and traditional peoples, an offshoot from the environmentalist movements, which involves the simultaneous defense of workplaces and environmental preservation. These are features that could strengthen social control with the aim of forming public policies, among them full health care for subsistence fishermen.

4 - Inclusion of fishing workers health protection measures within the scope of SUS Basic Care. There are various studies and examples indicating the importance of coordination between the Family Health Strategy and basic care services and occupational health protection ${ }^{19}$. As we have seen, the notion of the productive family in farming work or subsistence fishing is differs from the experiments of including occupational health programs in the FHS, which until then were centered on the idea of the consumer family with an income from wages. This perspective brings VISAT challenges for the CERESTs and the FHS in understanding the work processes that exist at the core of the family, which produces and generates income, and for simultaneous protection against endemic diseases and work related health threats. Practical examples are the availability of equipment for individual and collective protection, the association between vaccination programs in general and occupational vaccination, such as injections against tetanus, hepatitis $\mathrm{A}$ and 
yellow fever, and the inclusion of periodic occupational exams in programming the activities of the Family Health Units.

5 - Ensuring the consolidation under SUS of the system of referrals and counter-referrals for diagnosis, treatment and rehabilitation for work related illnesses, together with the systematic notification of such illnesses. The recognition of work related pathologies, by means of diagnoses undertaken until then in SESAO, indicates the possibilities for realizing such a program within the context of SUS mobile clinics and hospitals. In this connection, the actions of the CERESTS are central for the construction of a network of referrals for cases that require complex treatment within occupational health care.

6 - Provision of means to guarantee the right to accident insurance and to social security benefits. The subsistence fisherman is affiliated to the social security regime and needs to have his rights assured, as in the case of any other worker. The availability of financial support is essential for those suffering from RSI, for example, if they are to get away from exposure to excessive repetition of movement and undergo an effective treatment plan and physiotherapy. Moreover, the notification of illnesses to the social security system will allow the establishment of statistical and epidemiological data bases for the planning of preventive policies.

7 - Participation in inter-sectorial programs for the protection of children and adolescents. Social support through crèches and full time schools for children and adolescents, for example, contributes towards reducing child labor, allows the eradication of work related accidents and illnesses in children and adolescents, and replaces the inspection model with another centered on social development.

There are, therefore, challenges for VISAT with priority programs that can help to introduce changes in work processes that are responsible for dangers to health ${ }^{20}$ in subsistence fishing, such as shellfish gathering in mangrove swamps, which involves a variety of physical, biological, chemical and organic risks (contaminated mud), and a high degree of repetitive movements, the number of which equals those encountered by typists ${ }^{3}$.

We set out two examples below to show the possibilities for improvements in working conditions. The setting up of oyster production cooperatives has started in the North East region of Brazil, based on a radical technological change in the work process resulting from the substi- tution of oyster gathering by oyster farming. The family-based work structure in subsistence fishing continues, but the production process has changed from gathering to farming. In this process, floating platforms with baskets of oyster "seeds" are positioned on the sea, close to the shore. During the time the oysters are growing, the work consists in monitoring their progress and occasionally cleaning them. The greater size of the rafts means an increase in the time needed for cleaning, but the process takes place outside the mangrove swamps. This change is an advance economically and results in a big reduction in working hours. The exhausting daily activities in the mangrove swamps have gone, and with them some of the typical risks of oyster gathering. Some risks associated with the new practices persist, but in a lesser form, for example exposure to the sun and the travelling to and from work carrying heavy loads. Excessive repetitive movement is experienced only at the stage of preparing the oysters, when they are removed from their shells after being collected.

Another strategy for changing the work process is to be found in the cooperatives for the sale of fish and shellfish that exist in some fishing communities, the main aim of which is to eliminate the role of the middleman in the sale of shellfish. The organization of work remains based on the family structure, but the sale of the fish and shellfish is handled by a cooperative, which stores the products in appropriate refrigerators and sells them at a greater profit when compared with sales to the middlemen. In this trade cooperative, what each family receives depends on the quantity of products delivered, which means a considerable increase in income and a consequent improvement in working and living conditions.

In these cooperatives the requirements with regard to occupational health are similar to those of any small company in the commercial sector. The basic difference lies in the fact that they are not based on salaried relationships, but on self-employed personnel acting on behalf of the cooperative, who take general management decisions, including those with regard to the prevention of accidents and illnesses at work. And preventive medical examinations for work related illnesses could be associated with the carrying out of other tests required by Health Surveillance in food security to approve the sale of food. Periodic medical examinations or preventive screening could be carried out in the Family Health Unit of the municipality, which does not happen. 
These exams are a central strategy for the early diagnosis of work related illnesses in subsistence fishing and in the guidelines for VISAT programs focused on epidemiological data by means of diagnostic protocols for RSI in fishermen and shellfish gatherers. The strategy is inherent in a policy of full health care for people who work in the forest or on the water.

There are, for example, periodic examinations for the prevention of diabetes, arterial hypertension and breast cancer in all the FHUs. Here, where the principal local economic activity is shellfish production, the municipal or regional CEREST could issue guidelines to the FHU and establish referral and counter-referral systems in order to diagnose occupational health risks in periodic examinations associated with the general preventive exams. It would also be an important strategy as a source of information for implementing health surveillance actions by the Cerests. As in other sectors of production, such actions would be aimed at changing work situations that represented health risks. However, in this case, apart from analyzing the work processes, what is required is a particular understanding of the culture of these people, of the possibilities for, and limits on, the introduction of the necessary changes in these processes

As regards the prevention and control of risks at work, the costs of purchasing individual and collective protective equipment, the carrying out of periodic examinations, the procedures to establish causal connections for the purposes of social security, among other things, could jeopardize the economic survival of the fishermen. Popular knowledge and practice in methods of work have accumulated over a long period of time ${ }^{21}$. To ensure the economic stability and, at the same time, the way of life of these workers involves strategies for popular health education and the introduction of working methods and equipment for the protection of health, in the same way as provided by the structures for economic incentives that operate in these communities. This is possible, because there are a number of initiatives for the improvement of health and environmental conditions for certain categories of non-waged workers who are socially vulnerable. One example is the tax exemption for the financing of environmental protection projects and the improvement of flour mills, machinery, equipment and constructions financed by official banks.

\section{Final considerations}

The study of the work and health risks in subsistence fishing has been essential for the diagnosis of work related illnesses in this category, which remain invisible to the health information systems. This situation unfortunately reveals not only the absence of the right to health in these communities, but also the absence of the right to be recognized as ill and to receive the appropriate social security benefits. Here the experience of the UFBA mobile clinic, which has been detailed in this article, has been a priceless contribution that could serve as an example to other health services in Brazil. The information presented, although of local significance, points to the need for effective public policies for the extension of full health care to this significant proportion of workers.

From the standpoint of VISAT, as already pointed out, one of the basic strategies for improving the working conditions and, consequently, the health of this population centers on the reduction of the long hours of work, characterized particularly by intense physical effort and a great deal of repetitive activity. This debilitating work is the result of the economic exploitation that they suffer in their commercial dealings with middlemen, who appropriate to themselves the greater part of the fruits of their labor. At the present time, changing this picture means carrying out programs of an essentially political and educative nature designed to overcome certain traditional values that are firmly rooted in these workers and that limit the introduction of forms of association or other initiatives for adding value to natural products. 


\section{Collaborations}

PGL Pena took part in the practical research and in the preparation of the article; C Minayo Gomez has participated recently in the practical research and also played a part in conceiving and writing the article.

\section{References}

1. Brasil. Ministério da Pesca e Aquicultura. Boletim Estatístico da Pesca e Aquicultura, Brasil 2008-2009. Brasília: Ministério da Pesca e Aquicultura; 2010. [acessado 2014 maio 1]. Disponível em: http://www.presidencia. gov.br/estrutura_presidencia/seap/

2. Gorz A. Métamorphoses du travail quête du sens: critique de la raison économique. Paris: Galilée; 1988.

3. Pena PGL, Freitas MCS, Cardim A. Trabalho artesanal, cadências infernais e lesões por esforços repetitivos: estudo de caso em uma comunidade de marisqueiras na Ilha de Maré, Bahia. Cien Saude Colet 2011; 16(8):3383-3392.

4. Lima SM, Gomez CM. Construtores de casa e artífices de cidadania: Modos cooperativos de trabalhar e viver. Rev. Trab. Educ. Saúde 2008; 6(2):321-340.

5. Sachs I. L'Ecodéveloppement: stratégies pour le XXIe siècle. Paris: Syros; 1997.

6. Rosa MFM, Mattos UAO. A saúde e os riscos dos pescadores e catadores de caranguejo da Baía de Guanabara. Cien Saude Colet 2010; 15(Supl. 1):1543-1552.

7. Novalbos J, Nogueroles P, Soriguer M, Piniella F. Ocupational Health in the Andalusian Fisheries Sector. Occup Med (Lond) 2008; 58(2):141-143.

8. Brasil. Ministério da Saúde (MS). Cadernos de Atenção Básica. Brasília, 2000. [acessado 2014 jun 6]. Disponível em: http://bvsms.saude.gov.br/bvs/publicacoes/caderno atencao_basica_n1_p1.pdf

9. Kaerlev L, Jensen A, Nielsen PS, Olsen J, Hannerz H, Tüchsen F. Hospital contacts for injuries and musculoskeletal diseases among danish seafares and fishermen: a population-based cohort study. Scand J Public Health 2007; 35(5):481-489.

10. Rios AO, Rego RF, Pena PGL. Doenças em Trabalhadores da Pesca. Rev. baiana de Saúde Pub 2011; 35(1):175188.

11. Brasil. Ministério da Saúde (MS). Doenças Relacionadas ao Trabalho: manual de procedimentos para os serviços de saúde. Brasília: Editora MS; 2001.

12. Brasil. Ministério da Saúde (MS). Dor relacionada ao trabalho: Protocolo de complexidade diferenciada. 2012. [acessado 2014 jul 12]. Disponível em: http://bvsms. saude.gov.br/bvs/publicacoes/dor_relacionada_trabalho _ler_dort.pdf.

13. Kuorinka I, Forcier L. (rédacteurs et coordenateurs). Les lésions attribuables au travail répetitifs. Montréal: Maloine; 1995.

14. Cooper C, Palmer K. Repeated movements and repeated trauma affecting the musculoskeletal system. In: Baxter PJ, Aw T, Cockroft A, Durrington P, Harrington JM. Hunter's Diseases of occupations. London: Hodder Arnold Ed.; 2010. p. 687-712.

15. Brasil. Ministério da Previdência Social. Boletim Estatístico 2012. [acessado 2014 jan 11]. Disponível em: http://www.previdencia.gov.br/arquivos/office/4 120329-115930-269.pdf.

16. Verthein MAR, Gomez CM. As armadilhas: bases discursivas da neuropsiquiatrização das LER. Rev. Cien Saude Colet 2001; 6(2):457-470. 
17. World Health Organization (WHO). Sixtieth World Health Assembly: Agenda 12.13 Workers'health: global plan of action. WHA60. 26, may 2007. [acessado 2014 jan 11]. Disponível em: http://www.who.int/occupational_health/WHO_health_assembly_en_web.pdf; e http://www.who.int/gb/ebwha/pdf_files/WHA60/A60 _R26-en.pdf

18. Vasconcelos LCF, Machado JMH. Política Nacional de Saúde do Trabalhador: ampliação do objeto em direção a uma política de Estado. In: Gomez CM, Machado JMH, Pena PGL, organizadores. Saúde do trabalhador na sociedade brasileira contemporânea. Rio de Janeiro: Fiocruz; 2011. p. 37-66.

19. Dias EC, Rigotto RM, Augusto LGS, Cancio J, Hoefel MGL. Saúde ambiental e saúde do trabalhador na atenção primária à saúde, no SUS: oportunidades e desafios. Cien Saude Colet 2009; 14(6):2061-2070.

20. Gomez CM. Campo da saúde do trabalhador: trajetória, configuração e transformações. In: Gomez CM, Machado JMH, Pena PGL, organizadores. Saúde do trabalhador na sociedade brasileira contemporânea. Rio de Janeiro: Fiocruz; 2011. p. 23-36.

21. Barfknecht K, Merlo ARC, Nardi HC. Saúde mental e economia solidária: Análise das relações de trabalho em uma cooperativa de confecção de Porto Alegre. Rev. Psico e Soc 2006; 18(2):54-61.

Article submitted 03/09/2014

Approved 03/09/2014

Final version submitted 09/09/2014 